\title{
Research on Antibacterial and Antioxidation of Fermented Ham
}

\section{Xue-Jun LIU ${ }^{1, a}$, Jia-Hui WANG ${ }^{1, b}$, Chang ZHU ${ }^{2, c}$, Yu XU ${ }^{1, d}$, Rui TANG ${ }^{1, e}$, Xuan ZHANG ${ }^{1, f}$, Xue-Jun LIU *}

${ }^{1}$ College of Food Science and Engineering, Jilin Agricultural University, Changchun, Jilin, 130118, China

\author{
${ }^{2}$ Jilin Engineering Vocational College, Food Engineering Branch, Siping, Jilin,136000, China \\ aliuxuejun63@163.com, b412491945@qq.com, c14170567@qq.com, d1422491537@qq.com,

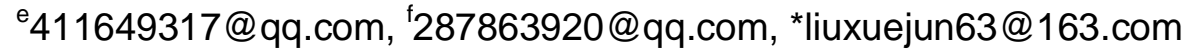

\section{Keywords: Fermented ham; Antibacterial; Antioxidation}

Abstract. Fermented ham is a kind of food that use lactic acid bacteria and other microbes to break down its protein and other nutrients. Fermented ham has excellent taste, unique flavor, and a lot of bioactive components, which has certain health function. At the same time, it can also plays a role in antibacterial and anti-oxidation. This review concluded the antibacterial and antioxidant properties of the fermented ham, which aims to provide theoretical basis for improving the quality of fermented meat products, and promotes the development of meat industry in China.

Fermented ham is a fermented meat product, which has the unique flavor, color, texture and a longer shelf life by the fermentation of the microorganism under the natural or artificial conditions. With the improvement of living standard, people pay more and more attention to food nutrition and health. Fermented ham in the fermentation process by the microbes, which has lower $\mathrm{pH}$, and a variety of biological active substances, which can inhibit the growth of bacterium, and also has a function of anti-oxidation, which can effectively improve the nutritional value and safety of fermented meat products and prolong the shelf life of products.

\section{Types of fermented meat products}

Fermentation of meat products have a long history in China, but mostly belong to natural fermentation, which seriously affecting the stability of quality of products. The reaserch and development about orientation microbial inoculation of fermented meat products also belong to a new field ${ }^{[1]}$. At present, fermentation of meat products are divided into fermented sausage and fermented ham in China ${ }^{[2]}$.

\section{Characteristics of fermented ham}

(1) Improve the nutrition and promote digestion

The microbial activities produce various proteases, which break down the proteins into various amino acids and polypeptides, at the same time also generate a series of acid, alcohol, nucleotide and other substances. Making the fermented ham easy to digest, absorb and promote nutritional value of fermented ham.

(2) Inhibit the formation of biogenic amines

Fermentation reduces the $\mathrm{pH}$ of ham to inhibit the growth of Clostridium botulinum, which could effectively inhibit the formation of biogenic amines and other biological toxins.

(3) Anti-cancer

The beneficial micro-organisms of fermented meat products colonized in the intestine, which 
has a protective effect on the intestinal tract and can effectively reduce the risk of carcinogens.

(4) The process of fermentation can promote the formation of bright color, improve structure, and also reduce the content of nitrite of products.

\section{Research on antibacterial and antioxidant properties of the fermented ham in China}

At present, the industry of fermentation ham is still in its early stage in China, and has not yet established the national standards, industry standards and corporate standards of fermentation ham. Yuecheng Meng ${ }^{[3]}$ et al. isolated and cultured staphylococcus on the surface of Jinhua ham in three different stages during the maturing process of fermented ham, to detect the presence of Staphylococcus aureus. The results showed that the branch of the four strains were staphylococcus xylosus, staphylococcus saprophyticus, Staphylococcus aureus and Staphylococcus aureus; Kezhong Lin $^{[4]}$ explained the relationship between the mold and the formation of the quality, flavor and color of Jinhua ham during the production process. They found that many fungi had inhibitory effects on the growth of spoilage bacteria; Yanke $\mathrm{Ma}^{[5]}$ et al. treated horse meat by salting, directional inoculating. The results showed that the raw meat was salted with $3 \mathrm{~d}$, and then inoculated with fine strains of fermentation, and fermented with 30d. It can significantly improve microorganisms, protein, moisture, nitrite, sodium chloride and texture characteristics of horse meat and meanwhile improve the quality, flavor and prolong the shelf life of meat products; Shuliang Liu ${ }^{[6]}$ et al. investigated the affection of artificial inoculation of compound bacteria on physicochemical and biological characteristics of specific meat. The figures suggested that physicochemical and biological properties of the meat products which inoculated of compound bacteria were much better than natural fermented meat products; Lujuan Xing ${ }^{[7]}$ et al. explored the antioxidant activity of crude peptide in traditional fermented meat products. The results showed that the extraction rate of crude peptides was $3.44 \%$, and its antioxidant activity increased with the increase of the concentration of crude peptides; Chaozhi Zhu ${ }^{[8]}$ et al. extracted the crude peptides and evaluated the ability of antioxidation by measuring the ability of free radical scavenging, chelated metal ions, inhibition of lipid peroxidation and protein oxidation in different concentrations of crude peptides, and compared to the same concentration of Butylated hydroxytoluene (BHT) and glutathione (GSH) for, to evaluate the antioxidant capacity of crude peptide solution of Jinhua ham. The results showed that with the increase of mass concentration, the antioxidant capacity of Jinhua ham was significantly increased.

\section{Research on antibacterial and antioxidant properties of fermented ham in foreign countries}

The study of fermented meat products in foreign countries focuses on the production process and screening, construction of fine microbial fermentation strains and so on; Geeta ${ }^{[9]}$ et al. explored the antioxidant and antibacterial properties by using lactic acid bacteria in chicken sausage which added the glucose and starch. The results showed that both raw and cooked fermented chicken sausage with addition of glucose and starch showed higher antioxidant on hydroxyl, superoxide anion and DPPH radical than the samples that did not add sugar, and the fermented chicken sausage with glucose and starch showed lower lipid oxidation and better sensory scores and less number of microorganisms; Joanna Stadnik ${ }^{[10]}$ et al. gave an overview of myogenic peptides.He noted that bioactive peptides are short amino acid sequences, and released from Proteins that may play different physiological roles, including anti-oxidation, antihypertensive, antibacterial, and other biological activities. It can be used as functional food and health food; Vladimir S. Kurćubić ${ }^{[11]}$ et al. investigated the extraction from Kitaibelia vitifolia insteaded of nitrite in Dry-cured and fermented 
sausage, and evaluated the effection on its antioxidant and antibacterial properties. The results showed that it can significantly improved the shelf life, safety of fermented sausages, and provided safe products for consumers; Rusthu.Pushpa S. Murthy. Amit Kumar Rai.N. Bhaskar ${ }^{[12]}$ investigated the antioxidant and antimicrobial properties of fermented hydrolyzate of freshwater fish head; The results showed that the fermentation process did not affect the distribution of fatty acids during the fermentation process. There were rich in protein hydrolysate, and showed DPPH radical scavenging capacity, at the same time with the ability of inhibition of antagonistic bacteria and pathogenic bacteria; P. Nedelcheva ${ }^{[13]}$ et al. Studied the antioxidant properties of fermented product with Lactobacillus plantarumNBIMCC2415 as a leavening agents. The results showed that probiotic strain NBIMCC2415 was able to inhibit the growth of pathogenic microorganisms such as Escherichia coli ATCC25922, E. coli ATCC8739G common Proteus, Salmonella sp. The high antioxidant properties of the strain were determined by oxidative free radicals. It was observed that the number of microorganisms in the dried marinated fermented sausage was reduced and the concentration of NBIMCC2415 was increased.

\section{Research progress of fermented ham}

In recent years, researches on fermented ham focus on the research and development of fine fermentation strains, and improve the fermentation process, fermentation conditions, reduce pollution in China and Forein countries. Hanjun $\mathrm{Ma}^{[14]}$ et al. generalized and assimilated of Western-style fermented Meat Products and combined with traditional Chinese sausage processing technology to explore the strains of Chinese fermented sausage and processing technology. The study confirmed that production of Chinese fermented sausage with Lactobacillus plantarum and Pseudomonas aeruginosa was better than any single strain; Essid ${ }^{[15]}$ et al. mixed Lactobacillus plantarum and S. aureus (S. xylosus) as a mixed-strain and inoculated to the traditional Toni fermentation sausage. The sensory parameters (aroma, color, taste and hardness) of sausages were found to be superior than those of non-inoculated natural fermented sausages; Lihua Zhao et al ${ }^{[16-17]}$. compared the effect of pentosaceus (P.pentosaceus) and mixed-srain (Lactobacillus and Aroma-producing staphylococci (S.carnosus)) on dry fermented sausages. It was found that the $\mathrm{pH}$ and Aw values of the pentosaceus group and the mixed-srain group were decreased during the maturation process, and the rate of decline in mixed-srain group was significantly faster than pentosaceus group, the color, hardness, chewiness, cohesion and adhesiveness of the final mixed-srain group were better than those of the pentosaceus group.

\section{Prospects}

With the improvement of people's living standards, People pay more attention to food nutrition and safety. Fermented ham has a good flavor, more nutritious and easy to digest. At the same time, the fermented ham has ability of prevention of cardiovascular disease and maintain the normal physiological function of the intestinal tract, and it has a longer shelf life. In recent years, there are a growing number of fermentation meat products in China, and make great progress.But we need to recognize that there still a big gap when compared with advanced world level. If we can combine our geographical advantages, customs with advanced production and processing technology, develop products with Chinese characteristics and constantly innovation, and put the product safety and quality in the first place, there will have a great progress of fermentation meat products industry in China. 


\section{Reference documentation}

[1] G Liu. Fermentation of Western ham[D]. Jiangsu: Jiangnan University, 2005. (In Chinese)

[2] X Bai, L Li, L Zhang. Fermented food and its safety evaluation[A]. 2015 Food Culture Development Conference Proceedings[C]. 2015.(In Chinese)

[3] Y Meng, R Ren, Y Lei. Jinhua ham in the process of maturation of Staphylococcus aureus detection[A]; the second session of China Zhejiang academic festival-food safety supervision and legal system construction and the second session of the Chinese food Graduate Forum Proceedings[C]. 2005. (In Chinese)

[4] K Lin, Y Yang, S Zhu, etc. Jinhua ham quality and color flavor formation and the relationship between mold[J]. Meat Research. (2):10-21. 1992. (In Chinese)

[5] Y Ma, J Yang. Directed inoculation fermented horse meat process and its nature[J]. Food Science and Technology. (10):154-157. 2010. (In Chinese)

[6] S Liu, Y Wang, K Yao, etc. The effect of compound bacteria on the physical and chemical properties of fermented meat products and biological characteristics[J]. Journal of Sichuan University: Engineering Science Edition. (4):185-190. 2010. (In Chinese)

[7] L Xing , Y Hu ,G Zhou , W Zhang. The identification of antioxidant activity of crude extraction peptides from Xuanwei ham[J]. Journal of Nanjing Agricultural University. (38):661-666. 2015. (In Chinese)

[8] C Zhu, W Zhang, $\mathrm{X} \mathrm{Xu}, \mathrm{G}$ Zhou. Jinhua ham crude peptide solution in vitro antioxidant activity[J]. Meat Research. (6):5-9. 2013. (In Chinese)

[9] Geeta, A.S. Yadav. Antioxidant and antimicrobial profile of chicken sausages preparedafter fermentation of minced chicken meat with Lactobacillus plantarum and with additional dextrose and starch[J]. LWT-Food Science and Technology, 73:249-258. 2017

[10] J Stadnik, P Kęska. Meat and fermented meat products as a source of bioactive peptides [J]. acta Scientiarum polonorum. Technologia Alimentaria. 14(3):181-190. 2015

[11] V.S. Kurćubić, P.Z. Mašković, E.M. Vujić, D.V. Vranić, S.M. Vesković-Moračanin, D.G. Okanović, S.V. Lilić. Antioxidant and antimicrobial activity of Kitaibelia vitifolia extract as alternative to the added nitrite in fermented dry sausage[J]. Meat Science. 97(4):459-467. 2014

[12]Ruthu, P.S. Murthy, A.K. Rai, N Bhaskar. Fermentative recovery of lipids and proteins from freshwater fish head waste with reference to antimicrobial and antioxidant properties of protein hydrolysate[J]. Journal of Food Science and Technology. 51(9):1884-1892. 2014

[13]P. Nedelcheva, Z. Denkova, P. Denev, A. Slavchev, A. Krastanov. Probiotic strain LactobaciLLus pLantarum NBIMCC2415 with antioxidant activity as a starter culture in the production of dried fermented meat products[J]. Biotechnology and Biotechnological Equipment. 24(1):1624-1630. 2010

[14]H Ma. Lactic acid fermentation of Chinese sausage bacteria and technology research[J]. Food Science. (8):25-28. 1997. (In Chinese)

[15]I Essid, M Hassouna. Effect of inoculation of selected Staphylococcus xylosus and Lactobacillus plantarum strains on biochemical, microbiological and textural characteristics of a Tunisian dry fermented sausage[J]. Food Control. 32(2):707-714. 2013

[16]L Zhao, Y Jin, C Ma etc. The effect of pediococcus and mixed-srain on the TPA and color of dry fermented sausages[J]. Chinese Journal of Food Science and Technology. (10):122-126. 2009. (In Chinese)

[17] H Hao, G Zhao. Meat products of the texture characteristics and research progress[J]. Food and machinery. 25(3):125-128. 2009. (In Chinese) 